\title{
CINEMA, QUADRINHOS E A SALA DE AULA: A REVOLUÇÃO IRANIANA GANHA IMAGEM E MOVIMENTO
}

\section{CINEMA, COMIC BOOKS AND THE SCHOOL CLASS: THE IRANIAN REVOLUTION GETS IMAGE AND MOVEMENT}

\author{
Bruno Ercole \\ Isabela Brasil \\ Mariana Zablonsky ${ }^{1}$
}

Resumo: O presente artigo é resultado das atividades do projeto PIBID UFPR: História e(m) Imagens, realizadas ao longo de 2014, e aborda questões relativas à utilização do cinema e das histórias em quadrinhos na sala de aula das séries finais do Ensino Básico. Partindo da discussão teórica acerca da validade destas mídias como fontes historiográficas e didáticas disponíveis ao professor, pretende-se apresentar exemplos práticos de como essa abordagem pode ser realizada. Para isso, utilizase do caso da oficina realizada sobre "Persépolis", em que os alunos Bolsistas do PIBID exploraram o tema da Revolução Iraniana em atividades aplicadas em duas escolas estaduais de Curitiba, utilizando-se do quadrinho "Persépolis" e da animação homônima, para abordar um assunto que não desfruta, via de regra, de grande destaque nos espaços escolares.

Palavras chave: Fontes; Cinema; Quadrinhos; Ensino; Revolução Iraniana; Persépolis.

Abstract: The following article is a result of the activities of the PIBID: História e(m) Imagens project, done in the year of 2014, and talks about the utilization of movies and comic books in the classes of final series in the basic education. Starting with a theorical discussion about the validi-

\footnotetext{
${ }^{1}$ Graduando e graduandas em História pela Universidade Federal do Paraná e bolsistas do programa PIBID - Projeto Institucional de Bolsas de Iniciação à Docência.
} 
ty of this kind of midia as historiografic and didatic source availables for the teacher, it is aimed to present pratical examples of how this approach can be done. For that, it is used the case of the activity made about "Persepolis", in which the students of the project explored the theme of the Iranian Revolution in activities executed in two public schools in Curitiba, using the Graphic Novel Persepolis and the homonymous animation, to approach a subject that, usually, does not have much prominence in the school spaces.

Keywords: Sources; Cinema; Comic books; Education; Iranian Revolution; Persepolis.

\section{Introdução}

Marc Bloch disse, nos anos 1940, que “... o bom historiador se parece com o ogro da lenda. Onde fareja carne humana, sabe que ali está a sua caça" (BLOCH, 2002: 54). Também nas palavras de Lucien Febvre, "A história (...) se edifica, sem exclusão, com tudo que o engenho dos homens pode inventar e combinar para suprir o silêncio dos textos, os estragos do esquecimento" (FEBVRE, 1989: 24). Seguindo este pensamento, somos levados a refletir sobre a importância da Indústria Cultural - essa massificação de produções, hoje considerada tão amplamente difundida que se configura como cultura que atinge o grande público - para a pesquisa e o ensino da história.

Não podemos negar que essas manifestações culturais, além de influenciar a própria sociedade, também são diretamente influenciadas por ela, e que o acesso a elas se encontra hoje de maneira cada vez mais facilitada. Dessas produções culturais que apresentam um sem número de variações, trabalharemos aqui duas: o cinema e as histórias em quadrinhos, focando na sua relação com a educação. 
Na primeira parte deste artigo apresentaremos brevemente a discussão teórica acerca da relação entre o cinema, os quadrinhos e o ensino de história. Através de estudo da bibliografia sobre o tema, buscamos trazer uma breve síntese da maneira como o professor pode trabalhar essas fontes em sala de aula.

Em um segundo momento do estudo, trataremos da oficina "Persépolis", elaborada pelos alunos do PIBID História e(m) Imagens, que foi aplicada em duas escolas públicas de Curitiba em Dezembro de 2014, onde foi trabalhada a Revolução Iraniana através do ponto de vista da personagem do quadrinho/animação, Marjane Satrapi. Com esse exemplo prático, buscamos demonstrar a maneira como as discussões teóricas acerca dessas novas fontes podem ser aplicadas no dia-a-dia das escolas, apontando, por fim, pontos positivos e negativos da realização da atividade.

\section{$O$ cinema no ensino de história}

Desde o surgimento do cinematógrafo em fins do século XIX seguido pela primeira exibição pública de um filme no subsolo de um café em Paris - até as grandes produções em 3D da atualidade, o cinema passou por muitas transformações. Afirmando-se desde a sua origem como um elemento da cultura de massa, ele opôs-se à exclusividade das manifestações culturais de elite. E, muito embora tenha sido considerado como uma atração de feira durante seus primeiros anos - alcunha não digna de muito crédito -, o cinema logo despertou o interesse dos mais diversos grupos sociais e, atualmente, a indústria cinematográfica é uma 
atividade multibilionária e com um alcance bastante amplo com relação aos seus públicos-alvo. E este potencial de transmissão de informações em grande escala já ultrapassou as fronteiras do mero entretenimento.

Para a pesquisadora Kornis (1992), a relação entre a história e o cinema foi percebida logo nos primeiros anos do desenvolvimento deste último. Contudo, o que se pensou inicialmente é que as imagens cinematográficas seriam uma representação incontestável dos eventos históricos, uma vez que eles estavam registrados em filme. Desde então, muito se discutiu sobre essa articulação - problematizando essa abordagem inicial -, principalmente depois dos anos 1960, com as obras de Marc Ferro, historiador francês que trabalhou as várias possibilidades de uso do cinema como fonte histórica.

No caso específico que tratamos aqui, o uso dos filmes nas aulas de história, podemos citar os estudos do pesquisador brasileiro Marcos Napolitano (2003). Para o autor, o interesse da escola pelo cinema é recente, embora o potencial dele para a educação das massas trabalhadoras tenha sido considerado desde seus primórdios. Segundo Napolitano, "A História é uma das disciplinas mais afeitas a atividades com cinema" (NAPOLITANO, 2003: 38). Ele cita o exemplo dos filmes históricos, um gênero já consagrado, com o qual, geralmente, se aprende mais sobre a sociedade que o produziu do que sobre o período que a obra representa.

Antes de tudo, o autor afirma que devemos compreender que a exibição do filme não substitui o trabalho do professor, pois este deve atuar como o mediador entre a obra e a análise proposta, guiando as 
discussões, levantando questões a serem debatidas pelos alunos. Assim, “o conhecimento não é 'algo' dado pela imagem; é construído através de problematizações; e no espaço escolar, essa construção dá-se na interação entre professor/aluno" (NASCIMENTO, 2008: 11). Tampouco o cinema deve ser usado em detrimento dos textos, uma vez que ambos podem ser utilizados de maneira complementar para o melhor desenvolvimento dos conteúdos em sala de aula.

Napolitano elenca alguns pontos básicos que devem ser observados para o trabalho com os filmes: verificar a possibilidade estrutural da exibição - condições como a disponibilidade da obra e de aparelhos de reprodução, tempo disponível; a adequação e pertinência deles ao conteúdo da disciplina; possibilidade do alcance das expectativas de trabalhar determinada obra com alunos - se despertará interesse pelos debates, se haverá o destaque para os conceitos que serão problematizados; e, por fim, deve-se atentar à faixa etária com a qual se trabalha, e planejar atividades distintas que estejam adequadas às suas realidades - abordagens mais profundadas, com grau de reflexão maior para os anos finais do Ensino Médio do que as utilizadas no Ensino Fundamental.

Também ocupando-se dessa articulação entre história e cinema na sala de aula, Nascimento (2008) nos oferece um roteiro prático para a realização deste tipo de abordagem.

Primeiramente, o professor deve ver o filme e, com um olhar crítico, tomar nota dos pontos relevantes para a sua discussão. Ele deve também procurar informações sobre a obra, seu contexto de produção, diretor, entre outros. O segundo passo é a elaboração de um plano de 
aula, que contemple os objetivos, os temas selecionados para a discussão e os métodos de avaliação - tendo em mente as limitações técnicas para a realização da atividade, como o tempo que disporá para a exibição do filme e para a discussão, por exemplo. Em terceiro lugar, está a apresentação do plano de aula aos alunos, que deve ser realizada ante da exibição do filme, a fim de que eles tenham informações acerca da atividade, para que assim possam direcionar a sua atenção e buscar na obra os elementos que serão utilizados na atividade. O último passo é a exibição e análise do filme propriamente ditas, quando o professor, como mediador, deve trabalhar as questões propostas no plano de aula que foi apresentado aos alunos, como, por exemplo, o destaque dado pelo diretos a determinadas cenas e ângulos, e como isso representa a visão que ele quer veicular na sua produção.

O roteiro que apresentamos aqui é apenas uma das muitas possibilidades de trabalho com o cinema nas aulas de história, e vale ressaltar também que essas atividades não estão livres de incorrerem em algumas armadilhas, como os anacronismos - julgando o que é apresentado no filme com os valores do presente. Outro problema que pode ocorrer é a credulidade excessiva, onde os alunos podem acabar tomando por absoluto e verdadeiro aquilo que se apresenta na tela. Devemos sempre lembrar que o cinema é dotado de licença poética e, diferentemente da historiografia, não tem um compromisso com uma verdade histórica. Trabalhar com essas questões a fim de evitá-las é tarefa que fica a cargo do professor. 
Procuramos aqui apresentar uma breve síntese da relação entre o Cinema e o ensino de História, porém ele não é a única mídia que pode ser trabalhada como fonte na sala de aula. Podemos encontrar também nas histórias em quadrinhos uma nova possibilidade de abordagem disponível para o professor.

\section{Os quadrinhos e a sala de aula}

Mais do que mera fonte de entretenimento, os quadrinhos, assim como o cinema, podem ser usados como uma ferramenta didática. A utilização da linguagem das histórias em quadrinhos em sala de aula pode ser percebida como uma forma não só de transmitir conhecimento, mas também de dinamizar o processo de ensino e aprendizagem e de tornar o conteúdo da disciplina mais próximo do cotidiano dos alunos.

Segundo Santos (2003), uma das maiores dificuldades em trabalharmos com esse tipo de narrativa nas escolas é derivada da visão equivocada que se tem sobre ela, a de que se trataria apenas de uma forma de entretenimento inocente e infantil. Para o autor é necessário que na utilização desse material em aula se ressalte o seu potencial reflexivo e crítico.

As histórias em quadrinhos oferecem a possibilidade de diversos usos, para debater, ilustrar, introduzir e aprofundar um determinado tema. Para tanto, seriam necessários conhecimentos por parte dos docentes e discentes sobre os elementos que compõe esse tipo de narrativa e sobre as obras que são usadas para esses fins. Tendo em vista que os quadrinhos são fundamentados em elementos verbais e não verbais os 
alunos teriam de dominar minimamente o código especifico desse tipo de linguagem, que envolve elementos como os diferentes formatos de publicação - tiras, charges, graphic novels, os elementos visuais - o requadro, os balões, as onomatopeias -, e também os aspectos que se ligam à representação dos personagens, do tempo e da narração.

Para Vilela (2004), durante as atividades propostas pelos professores de história que envolvam os quadrinhos, esses devem ser analisados por outras perspectivas. Para o autor, contextualizar a obra utilizada na aula, referenciar a época em que foi produzida, é essencial para a compreensão dos alunos sobre o conteúdo histórico exibido, pois auxiliaria no entendimento sobre a forma na a qual narrativa foi construída. Além das temporalidades que envolvem a história em quadrinhos, seria relevante igualmente discutir sobre o autor que a deu origem. A vida dele muitas vezes é retratada de diferentes maneiras nas suas sobras, e então compreender essas maneiras e tentar entender as suas intenções ao realiza-las é essencial para a melhor análise da obra.

$\mathrm{O}$ uso dos quadrinhos como uma ferramenta para interpretar as narrativas sobre o passado no ensino básico pode ser realizado de duas principais maneiras, de acordo com o que fala Palhares (2008). Na primeira delas, o professor explana informações fundamentais sobre determinado assunto, introduzindo posteriormente quadrinhos que dialogam com o tema por ele apresentado. Tendo isso como base, o professor poderia então solicitar que os alunos analisassem a maneira como o assunto foi tratado pela obra. Outra opção seria apresentar um quadrinho 
aos estudantes e fazer com que estes buscassem extrair dessa fonte o seu conteúdo histórico e em seguida debater sobre ele.

A produção pelos alunos também é uma alternativa incentivada por muitos autores que tratam do ensino por meio dos quadrinhos. É vista como uma forma de avaliar a compreensão do estudante sobre conteúdo, exigindo dele criatividade e habilidades, como a de utilizar termos corretos para tratar de determinadas épocas, de não incorrer em anacronismos. Palhares sugere que se entregue os balões dos quadrinhos em branco para que os alunos preencham. Dessa maneira, estes interagiriam não só com a obra, mas também com os conteúdos históricos.

Por se tratarem de obras extremamente lúdicas, os quadrinhos aparecem como um ótimo recurso para o ensino. Um bom planejamento, que contemple a discussão sobre as estruturas do quadrinho, seu autor, as temáticas que ele envolve - e no caso de quadrinhos históricos - do período que ele trata e o contexto em que está inserindo, possibilita aos professores que os utilizam nas atividades das suas aulas de história instigar a reflexão crítica entre os estudantes e construir um conhecimento histórico abrangente, que vai além da reprodução dos livros didáticos.

As maneiras apresentadas figuram dentre as muitas opções de trabalhar a relação entre essas novas mídias e o ensino de história. Podemos observar essa relação em um exemplo prático, a oficina "Persépolis", esforço que tentou unir cinema, quadrinhos e a sala de aula. 


\section{O uso do quadrinho e do filme "Persépolis" em sala de aula}

Uma interessante forma de trabalhar não só a história da Revolução Iraniana de 1979, mas também as questões relacionadas à religião muçulmana, ao papel da mulher nas sociedades islamizadas e a violência em zonas de conflito, pode ser encontrada no romance escrito por Marjane Satrapi ${ }^{2}$, na forma da história em quadrinhos "Persépolis", a qual mais tarde se tornou um filme francês de animação. A utilização da linguagem de HQs possibilita que a história seja contada de forma mais descontraída, tanto no que se refere ao processo histórico iraniano quanto aos fatos ocorridos na vida de Satrapi, o que pode estimular mais os alunos a estudarem o tema. Além disto, como há um filme sobre a obra permite, da mesma forma que os quadrinhos, que o aluno tenha acesso a uma linguagem mais simples sobre os complexos temas trabalhados pela autora.

Satrapi conta sua história até 1994, quando mudou-se pela segunda vez do Irã com destino à Europa. Antes disso, ela narra, a partir da relação com sua politizada família, a percepção e o modo pelo qual via e entendia os acontecimentos relacionais à derrubada do Xá Reza Pahlavi,

\footnotetext{
${ }^{2}$ Marjane Satrapi nasceu em Rasht, no Irã, em 1969. Estudou no liceu francês de Teerã, onde passou a infância. Bisneta de um imperador do país, teve uma educação que combinou a tradição da cultura persa com valores ocidentais e de esquerda. Aos catorze anos, partiu para o exílio na Áustria, e depois retornou ao Irã a fim de estudar belas-artes. Publicou sua obra autobiográfica Persépolis a partir do ano 2000 e, em 2007, dirigiu a animação homônima junto com Vincent Parounnaud. Atualmente estabelecida na França, trabalha como ilustradora e autora de livros infantis.
} 
em 1979, e a subida ao poder dos líderes xiitas. Sendo assim, a história da civilização Persa e, principalmente, do Irã no século XX, preenche os quadros da história em quadrinhos e do filme, evidenciando as transformações sociais e de comportamento ocorridas após a chegada dos xiitas ao poder. A utilização do véu pelas mulheres, os novos conteúdos ensinados nas escolas, a perseguição política aos opositores do regime e as consequências da Guerra Irã-Iraque são tratados pela autora com um aguçado senso de humor em muitas passagens. Uma perspectiva feminista de oposição à opressão sofrida pelas mulheres no país do Oriente Médio é constantemente referenciada nas obras.

\section{A Oficina "Persépolis"}

Em 2014, a equipe do projeto História e(m) imagens do PIBID UFPR, preparou uma oficina, aliando a HQ e a animação, para ser aplicada com os alunos dos colégios estaduais Bento Munhoz da Rocha e Vitor Ferreira do Amaral. Sob a supervisão dos professores Fabiano Stoiev no primeiro colégio, e Victor Cuneo no segundo, aplicamos uma atividade com os alunos de variadas séries, visando trabalhar os temas tratados por Satrapi. Foram selecionados trechos da animação que abordavam a Revolução Iraniana de 1979 e fragmentos da HQ que trabalhavam o papel da mulher, o uso do véu, hijab, na sociedade iraniana das décadas de 1970/80 e a opressão do novo governo estabelecido após a Revolução. O principal objetivo da oficina consistiu em apresentar o filme e a história em quadrinhos como uma nova maneira de trabalhar 
temas históricos. Além disto, explorar e questionar os temas levantados pela autora.

A oficina trabalhou três temáticas centrais: a religião islâmica, as mulheres no islamismo e Revolução Iraniana de 1979. Acerca do Islã, questionamos os alunos sobre se conheciam algo da religião islâmica, como quem é o profeta Maomé e o que é o alcorão para os muçulmanos. Desta forma, foi apresentada uma breve explicação sobre o Islã, seus preceitos, componentes e divisões. A respeito do papel da mulher nesta religião levantamos perguntas relativas a temas recorrentes no quadrinho e na animação: o uso do hijab e a influência que tal prática tem na vida das mulheres. Os alunos também foram indagados sobre o Irã, a teocracia vigente no país e a Revolução de 1979 que depôs o então governante. Centrando neste eixo temático, propusemos que os estudantes trouxessem seu conhecimento sobre os tópicos citados e apresentassem também suas dúvidas e opiniões.

Sendo assim, uma das maiores dificuldades que encontramos foi a exploração dos temas históricos, uma vez que a grande maioria dos estudantes desconhecia a Revolução Iraniana e possuía pouco ou nenhum conhecimento sobre a religião islâmica. Além disto, as oficinas englobavam alunos de variadas séries e, desta forma, havia alunos da quinta série do ensino fundamental ao primeiro ano do ensino médio. Esta variedade afetou a profundidade das discussões realizadas e até mesmo a direção que estas tomaram, focando-se mais na questão da função da mulher na sociedade islâmica. Outra questão de destaque é a falta de apelo que leitura dos quadrinhos teve nos estudantes: muitos deixaram a 
oficina ao terem que realizar a leitura do quadrinho e empreender a discussão dos temas propostos.

Após a realização das oficinas, percebemos as dificuldades de se utilizar uma HQ e um filme que englobassem temas complexos e distantes dos alunos, visto que a Revolução Iraniana, a religião muçulmana e até o papel da mulher na sociedade islâmica são temas afastados do cotidiano de estudos históricos dos alunos. Sendo assim, através desta primeira experiência, pudemos adquirir o conhecimento prático da utilização de quadrinhos e filmes na sala de aula, trazendo para o grupo as dificuldades a serem transpostas em uma próxima abordagem. Contudo, o quadrinho de Satrapi, assim como a animação, trazem para os alunos a realidade de um mundo distante dos seus cotidianos, explorando temas que até então eram desconhecidos e levantando questões que pertencem não só ao mundo islâmico, mas também a realidade brasileira.

\section{Considerações finais}

Ao longo dessas páginas procuramos trabalhar um pouco a relação entre o cinema, as histórias em quadrinhos e as aulas de história. A utilização dessas novas fontes no ensino é um tema complexo, ainda alvo de bastante discussão teórica, porém já se afirma como uma interessante alternativa para o professor que busca meios diferentes de trabalho com fontes didáticas, pois as abordagens acabam por sair do cotidiano mais tradicional da sala de aula, o que tende a despertar o interesse e a curiosidade dos alunos. Assim, o professor pode tentar fazer uso do cinema e dos quadrinhos, organizando essas abordagens de maneira 
para que tenham espaço à despeito do cronograma mais rígido exigido pelas escolas.

Essas intervenções podem ser algo muito benéfico, uma vez que também dão a oportunidade para o professor desenvolver conteúdos que talvez não tivessem tanto destaque no calendário acadêmico, ou mesmo apresentar o lado prático de temas cuja teoria é de difícil assimilação pelos alunos, como buscamos fazer através da oficina que é apresentada neste artigo.

Contudo, através do exemplo prático, pudemos identificar também alguns problemas que podem surgir com a aplicação dessas atividades. Após a realização das oficinas, percebemos as limitações de se utilizar uma HQ e um filme que englobassem temas complexos e distantes dos alunos, visto que a Revolução Iraniana de 1979, a religião muçulmana e até o papel da mulher na sociedade islâmica são temas afastados do seu cotidiano e de seus estudos históricos. Em função disso, eles tiveram algumas dificuldades em participar das discussões propostas. Sendo assim, através desta primeira experiência pudemos adquirir o conhecimento prático da utilização de quadrinhos e filmes na sala de aula, trazendo para o grupo as dificuldades a serem transpostas em uma próxima abordagem. Neste sentido, uma das alternativas elaboradas é a aproximação dos temas ao cotidiano brasileiro, por meio de analogias e reflexões acerca com a realidade vivenciada pelos próprios alunos, além da escolha de quadrinhos e filmes que sejam mais conhecidos.

O quadrinho de Satrapi, assim como a animação, trazem para o aluno as especificidades e a realidade de um mundo distante do seu co- 
tidiano. Ele explora temas que até então eram desconhecidos o que, ainda que com algumas limitações, os torna de grande valia para o professor em sala de aula.

Por fim, é importante ressaltarmos que, embora à primeira vista o uso dessas mídias em sala de aula pode parecer uma atividade fácil, ela não pode ser aplicada de maneira leviana. $\mathrm{O}$ trabalho com o cinema $\mathrm{e}$ com os quadrinhos na escola é algo bem mais complexo, que envolve tanto a preparação técnica quanto a do professor, além de ser uma abordagem que está diretamente relacionada ao interesse e à reação dos próprios alunos. Não sendo tidas como substitutas aos livros e ao trabalho do professor, essas novas abordagens servem para complementar o ensino e auxiliam no desenvolvimento de temas mais complexos e distantes.

\section{Referências bibliográficas}

\section{Fontes}

PERSÉPOLIS. Direção de Marjane Satrapi e Vincent Parounnaud. França: 2.4.7 films, 2007. 1 DVD (96min), cores.

SATRAPI, Marjane. Persépolis. 1. ed. São Paulo: Companhia das Letras, 2007.

\section{Obras consultadas}

BLOCH, Marc. Apologia da história ou o ofício do historiador. Rio de Janeiro: Jorge Zahar, 2002.

FEBVRE, Lucien. De 1892 a 1933: Exame de consciência de uma história e de um historiador. In.: Combates pela história. Lisboa: Editorial Presença, 1989. 
KORNIS, Mônica Almeida. História e cinema: um debate metodológico. Estudos históricos, Rio de Janeiro, v.5, n.10, p.237-250, 1992.

NAPOLITANO, Marcos. Como usar o cinema na sala de aula. São Paulo: Contexto, 2003.

NASCIMENTO, Jair Carvalho. Cinema e ensino de história: realidade escolar, propostas e práticas na sala de aula. Revista de História e Estudos Culturais, v. 5, n. 2, p.1-23, abril/ maio/ junho de 2008. Disponível em:< http://www.revistafenix.pro.br/PDF15/Artigo_05_\%20 ABRILMAIO-JUNHO_2008_Jairo_Carvalho_do_Nascimento.pdf.>. Acesso em: 01/05/20 15 .

PALHARES, Marjory Cristiane. História em Quadrinhos: Uma Ferramenta Pedagógica para o Ensino de História. Trabalho de Conclusão do Programa de Desenvolvimento Educacional. Disponível em: <http://www.diaadiaeducacao.pr.gov.br/portals/pde/arquivos/22 6 2-8.pdf.> Acesso em 5 de maio 2015.

SANTOS, Roberto Elísio dos. A história em quadrinhos na sala de aula. In: intercom - sociedade brasileira de estudos interdisciplinares da comunicação congresso brasileiro de ciências da comunicação. Disponível em:

<www.intercom.org.br/papers/nacionais/2003/www /pdf/2003_NP11_santos_robert.pdf.>. Acesso em: 05 de maio 2015.

VILELA, Túlio. Os quadrinhos na aula de História. In: BARBOSA, Alexandre et al. Como Usar as Histórias em Quadrinhos na Sala de Aula. São Paulo: Editora Contexto, 2004. p. 101-135.

Recebido em: 08/06/2015 Aceito em: 08/12/2015 